\title{
Mineralogy and Magnetic Behavior of Yellow to Red Xuanhua-Type Agate and Its Indication to the Forming Condition
}

\author{
Danyi Zhou ${ }^{1,2} \mathbb{D}$, Guanghai Shi ${ }^{2} * \mathbb{D}$, Suzhen Liu $^{3}$ and Bailing $\mathrm{Wu}^{3}$ \\ 1 Beijing Institute of Gemology, National Gems \& Jewelry Technology Administrative Center, Ministry of \\ Natural Resources, Beijing 100013, China; zhoudy@ngtc.com.cn \\ 2 State Key Laboratory of Geological Processes and Mineral Resource, China University of Geosciences, \\ Beijing 100083, China \\ 3 State Key Laboratory of Lithospheric Evolution, Institute of Geology and Geophysics, Chinese Academy \\ of Sciences, Beijing 100029, China; liusuzhen@scichina.org (S.L.); onlywbl@126.com (B.W.) \\ * Correspondence: shigh@cugb.edu.cn; Tel.: +86-10-82321836
}

Citation: Zhou, D.; Shi, G.; Liu, S.; $\mathrm{Wu}, \mathrm{B}$. Mineralogy and Magnetic

Behavior of Yellow to Red

Xuanhua-Type Agate and Its Indication to the Forming Condition. Minerals 2021, 11, 877. https:// doi.org/10.3390/min11080877

Academic Editors: Franca Caucia and Luigi Marinoni

Received: 12 July 2021

Accepted: 10 August 2021

Published: 13 August 2021

Publisher's Note: MDPI stays neutral with regard to jurisdictional claims in published maps and institutional affiliations.

Copyright: (c) 2021 by the authors. Licensee MDPI, Basel, Switzerland. This article is an open access article distributed under the terms and conditions of the Creative Commons Attribution (CC BY) license (https:// creativecommons.org/licenses/by/ $4.0 /)$.
Abstract: Iron oxides/hydroxides are important magnetic minerals to provide information about changes in the forming environment. However, the magnetic behavior in agate has been rarely investigated. In this study, the magnetic behavior of the Xuanhua-type agate with intense yellow to red colors from the Xuanhua District (China) was investigated by temperature dependence of magnetic susceptibility, hysteresis loop, isothermal remanent magnetization and the analysis of remanent coercivity components from the gradient acquisition plot. Yellow goethite and red hematite can be quantitatively identified by XRD and Raman spectroscopy due to their relatively higher content. Results showed that the red, yellow and orange Xuanhua-type agate had different magnetic behavior, and magnetite existed in the yellow and orange ones. Fluid inclusions in such agate had the homogenization temperature of $\sim 168{ }^{\circ} \mathrm{C}$ to $264{ }^{\circ} \mathrm{C}$. All results suggested that the dehydration of goethite to form hematite was the main reason for the high remnant coercivity (above $1000 \mathrm{mT}$ ) of hematite in the red agate. The co-existence of magnetite and goethite in the yellow and orange agate reflects the transformation from $\mathrm{Fe}^{2+}$ to $\mathrm{Fe}^{3+}$, indicating the change in the redox property of the environment. Unique patterns mainly formed by hematite and goethite make it a popular gem-material with high research value.

Keywords: magnetic behavior; yellow goethite; red hematite; Xuanhua; agate; formation; mineralogy

\section{Introduction}

Agate, formed by hydrothermal fluid filling the pores or cavities in igneous rocks, is mainly composed of $\alpha$-quartz with minor impurities. Among its multiple colors, the range from yellow to red is usually caused by iron oxides/hydroxides (especially hematite and goethite) [1,2] which show weak magnetic properties at ambient conditions.

Iron oxides/hydroxides are widely distributed in nature and common in soil and rocks, among which goethite and hematite are more thermodynamically stable at ambient temperature and are often the end members of many transformations [3]. The magnetic characteristics of these iron oxides/hydroxides have been used to provide information on the change in the environment and climate, genesis and trace mineral identification [4-12]. However, most studies concerning the rock magnetic properties of iron oxides/hydroxides focus on natural single mineral aggregates, synthesized minerals, or the minerals sieved and selected from soil and sediments $[13,14]$. There lacks investigation on the magnetic behavior of iron oxides and hydroxides in agate. However, because the main mineral component is diamagnetic quartz and a few kinds of Fe-bearing minerals, yellow to red agate can be regarded as an excellent material for studying the magnetic behavior of iron oxides/hydroxides formed in the hydrothermal environment. However, due to their low 
content under the detection limit of XRD, iron oxides/hydroxides in most agate are usually identified by a laser Raman spectrometer which cannot provide quantitative data of their content. Therefore, there is a need for more investigation to find the relationship between magnetic behavior, the variety and the content of iron oxides/hydroxides in such an agate.

Nevertheless, a new variety of agate with intense yellow to red colors was found in the Xuanhua District (in Zhangjiakou, Hebei province, China) in recent years and is commercially called Xuanhua agate in the Chinese jewelry market. Its intense color indicates a high content of iron oxides/hydroxides, making such agate an ideal sample for discussing the magnetic behavior of yellow to red agate. A few studies of Xuanhua agate have been performed and have confirmed the presence of hematite and goethite. However, these investigations mainly focused on the gemological properties, microstructure features and geological characteristics [2,15-18]. The magnetic behavior of iron oxides and hydroxides in Xuanhua agate and its indication to the formation condition need further discussion.

In this study, magnetic behavior of yellow to red agate was investigated by the temperature dependence of magnetic susceptibility ( $\chi$-T curves), hysteresis loop, isothermal remnant magnetization (IRM) and the analysis of remnant coercivity components (based on IRM curves). Based on the information of mineral composition and the content obtained from the Raman spectra and X-ray diffraction patterns as well as the temperature measuring of fluid inclusions, the indication of these magnetic characteristics to the forming condition of yellow to red agate from Xuanhua District was further discussed.

\section{Materials and Methods}

All investigated samples were collected from the Xuanhua agate deposit. The area of this deposit is about $20 \mathrm{~km}^{2}$, located near Dishuiya Village, Xuanhua District, Zhangjiakou, Hebei Province, China, and belongs to the northern margin of the North China Craton. The subduction of the palaeo-Pacific plate to the Eurasian plate was intense from the Late Jurassic to Early Cretaceous period, and a series of intermediate-acid igneous rocks were formed by volcanic eruptions on the surface [19-21]. The strata of the Xuanhua agate mining area mainly consists of the Jurassic Tiaojishan formation $\left(\mathrm{J}_{2} \mathrm{t}^{1} \sim \mathrm{J}_{2} \mathrm{t}^{5}\right.$ from bottom to top), the Jurassic Houcheng formation $\left(\mathrm{J}_{3} \mathrm{~h}\right)$, the Cretaceous Zhangjiakou formation $\left(\mathrm{J}_{3} \mathrm{z}\right)$, and the Cenozoic Quaternary loess $\left(\mathrm{Q}_{4}\right)$ (Figure 1). Xuanhua agate occurs as an amygdaloid, ellipsoidal or vein shape in the pores or fractures of trachyte of the Jurassic Tiaojishan formation [17,18] (Figure 2a,b). The agate-bearing terrane is about $3.5 \mathrm{~km}$ in length of EW, $3.3 \mathrm{~km}$ in width of SN and several meters deep.

Compared with other agate, the intense colors (mainly red, yellow and orange) and low transparency (translucent to opaque) are the outstanding feature of the Xuanhua agate (Figure 2c). In this investigation, five representative samples numbered $\mathrm{XH}-05$ (yellow), XH-02-Y (intense yellow), XH-02-R (orange), XH-D-01 (red) and XH-D-02 (intense red) were selected from a large collection of Xuanhua agate samples. These samples were shaped into different forms for different experiments: a cube with the length of $1 \mathrm{~cm}$ for the measurement of hysteresis loop and IRM, powder with the grain size under $74 \mu \mathrm{m}$ for the experiments of $\chi$-T curves and X-ray diffraction, and some pieces of slice with the thickness about $30 \mu \mathrm{m}$ for microscopic observation.

Mineral components were determined through Raman spectroscopy and X-ray diffraction. The Raman spectroscopy study was performed by a Renishaw-inVia microscope at room temperature, with a laser source of $532 \mathrm{~nm}$ at $10 \mathrm{~mW}$ in mode laser power at $100 \%$, the Raman shift range from 100 to $2000 \mathrm{~cm}^{-1}$, and testing spot size of $1 \mu \mathrm{m}$. X-ray diffraction patterns were obtained by Bruker D8 Advance X-ray power diffractometer, with the angle range from $10^{\circ}$ to $65^{\circ}$ with a step length of $0.02^{\circ} /$ step and scanning speed of $0.25^{\circ} / \mathrm{min}$. The mineral contents were calculated by the relative intensity ratio of diffraction peaks of different phases and the detection limit of this diffractometer is $0.5 \mathrm{wt} \%$. Microphotographs of magnetic minerals were captured by OLYMPUS BX51 polarized microscope with magnification of $500 \times$. 


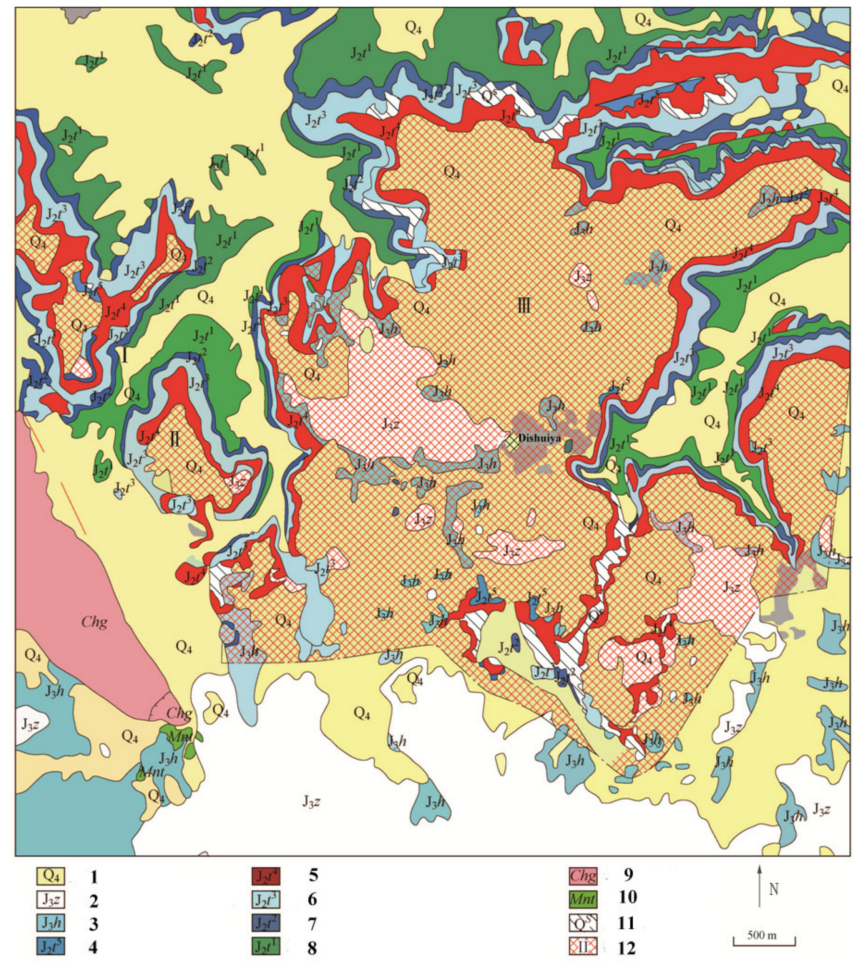

Figure 1. Geological map of Xuanhua agate deposit and its adjacent areas (modified after [17]): 1 Quaternary loess; 2 rhyolitic tuff; 3 siltstone; 4 agglomerate tuff and tuffaceous breccias; 5 vesicular trachyte; 6 massive trachyte; 7 tuffaceous siltstone and volcanic breccias; 8 basalt; 9 dolomite of the Mesoproterozoic Changcheng formation; 10 bentonite deposit; 11 Qml; 12 agate-bearing zones and their number.
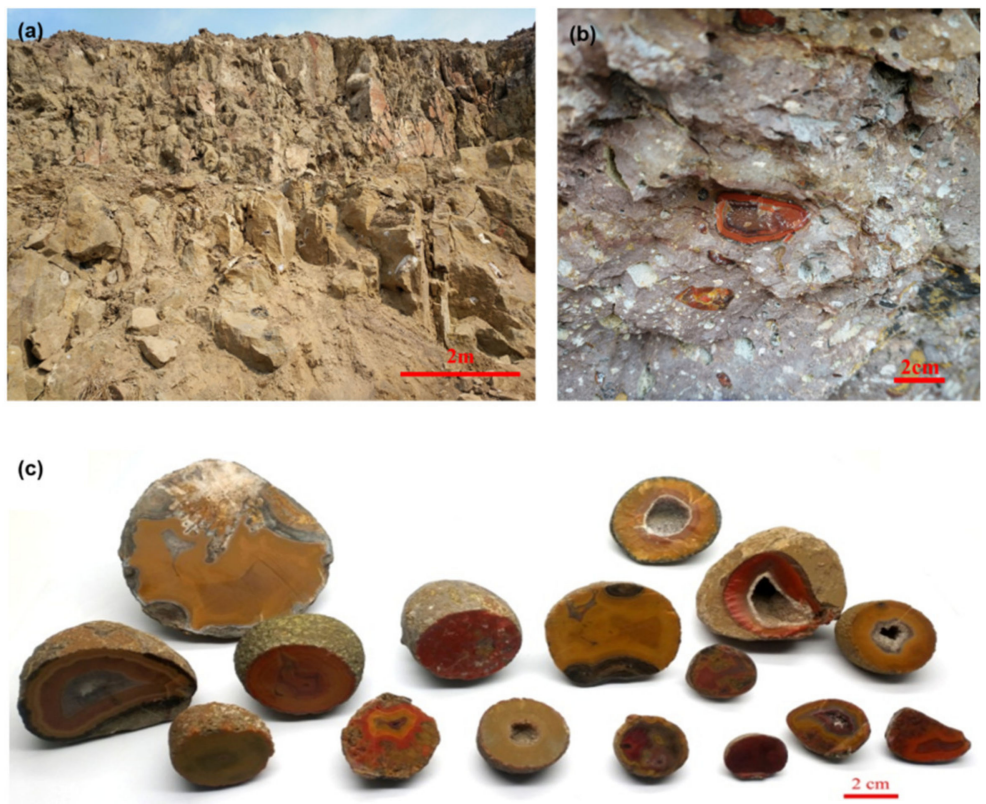

Figure 2. The deposit (a), geological occurrence (b) and typical samples (c) of Xuanhua agate.

Temperature dependence of magnetic susceptibility ( $\chi$-T curve) was performed in an Ar atmosphere using KLY-3S Kappa bridge with the CS-3 temperature control system. Samples were heated from $25^{\circ} \mathrm{C}$ to $700{ }^{\circ} \mathrm{C}$ and cooled back to $25^{\circ} \mathrm{C}$ at a rate of $12{ }^{\circ} \mathrm{C} / \mathrm{min}$. The heating and cooling curves can provide information on the mineral alternation of the samples. 
Hysteresis loops, acquisition curves of isothermal remnant magnetization (IRM) and their back-field demagnetizations were measured with MicroMag Model 3900 Vibrating Sample Magnetometer (VSM, sensitivity $=0.5 \times 10^{-9} \mathrm{Am}^{2}$ ) up to a maximum field of $1.5 \mathrm{~T}$ with a field increment of $2 \mathrm{mT}$ and averaging time of $200 \mathrm{~ms}$. The saturation magnetization $(\mathrm{Ms})$, the saturation remnant magnetization $(\mathrm{Mrs})$ and coercivity $(\mathrm{Hc})$ were acquired from hysteresis loops after the correction for the paramagnetic slope (at $70 \%$ of the maximum field). The remnant coercivity ( $\mathrm{Hcr}$ ) was obtained from IRM curves which can be transferred to the linear acquisition plot(LAP) and the gradient acquisition plot(GAP) to offer information about remnant coercivity components.

Fluid inclusion measurements were completed with the Linkam THMSG600 heatingfreezing stage attached to an Olympus BX51 microscope equipped with $5 \times, 10 \times, 50 \times$ and $100 \times$ long working distance Olympus objectives. The stage was capable of measurements in the range of $-196{ }^{\circ} \mathrm{C}$ to $600{ }^{\circ} \mathrm{C}$. The temperature increased at the rate of $0.2{ }^{\circ} \mathrm{C} / \mathrm{min}$ until total homogenization after the gas in the fluid inclusions turn smaller and the results were within the error of $\pm 0.2^{\circ} \mathrm{C}$. Prior to carrying heating and cooling measurements, the stage was calibrated with synthetic $\mathrm{H}_{2} \mathrm{O}$ and international pure $\mathrm{H}_{2} \mathrm{O}$ inclusion standard. The homogenization temperature was recorded after each experiment.

\section{Results}

\subsection{Major Mineral Components}

Under polarized microscope, yellow to red minerals are in dot shape with submicron to micron size (Figure 3a-c). Raman spectra show that the agate samples mainly consist of $\alpha$-quartz. In addition, the red, yellow and orange colors are separately caused by the presence of hematite, goethite and the mixture of hematite and goethite (Figure $3 \mathrm{~d}-\mathrm{f}$ ). Compared with most agate, the XRD patterns of Xuanhua agate (Figure 4a-e) can provide the content information of these Fe-bearing minerals: $1.1 \mathrm{wt} \%$ and $1.9 \mathrm{wt} \%$ hematite in red samples, XH-D-01 (Figure 4a) and XH-D-02 (Figure 4b), respectively; $0.9 \mathrm{wt} \%$ and $3.6 \mathrm{wt} \%$ goethite in yellow samples XH-05 (Figure 4c) and XH-02-Y (Figure 4d), respectively; orange sample XH-02-R (Figure $4 \mathrm{e}$ ) has the mixture of $0.8 \mathrm{wt} \%$ hematite and $0.5 \mathrm{wt} \%$ goethite. The relatively simple mineral composition makes such agate an excellent material for the study of natural iron oxides/hydroxides in a hydrothermal environment.
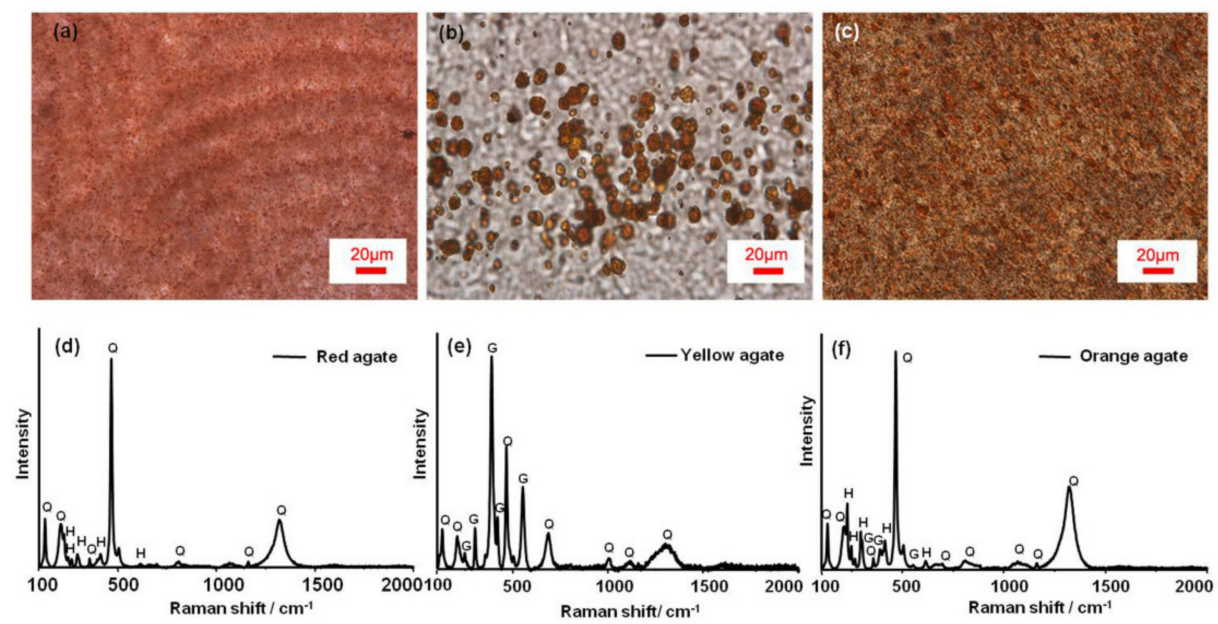

Figure 3. Micrographs of yellow goethite and red hematite of Xuanhua-type agate. (a) Hematite in the red agate; (b) goethite in the yellow agate; (c) mixture of hematite and goethite in the orange zone; (d-f) Raman spectra of red agate, yellow agate and orange agate, respectively. 


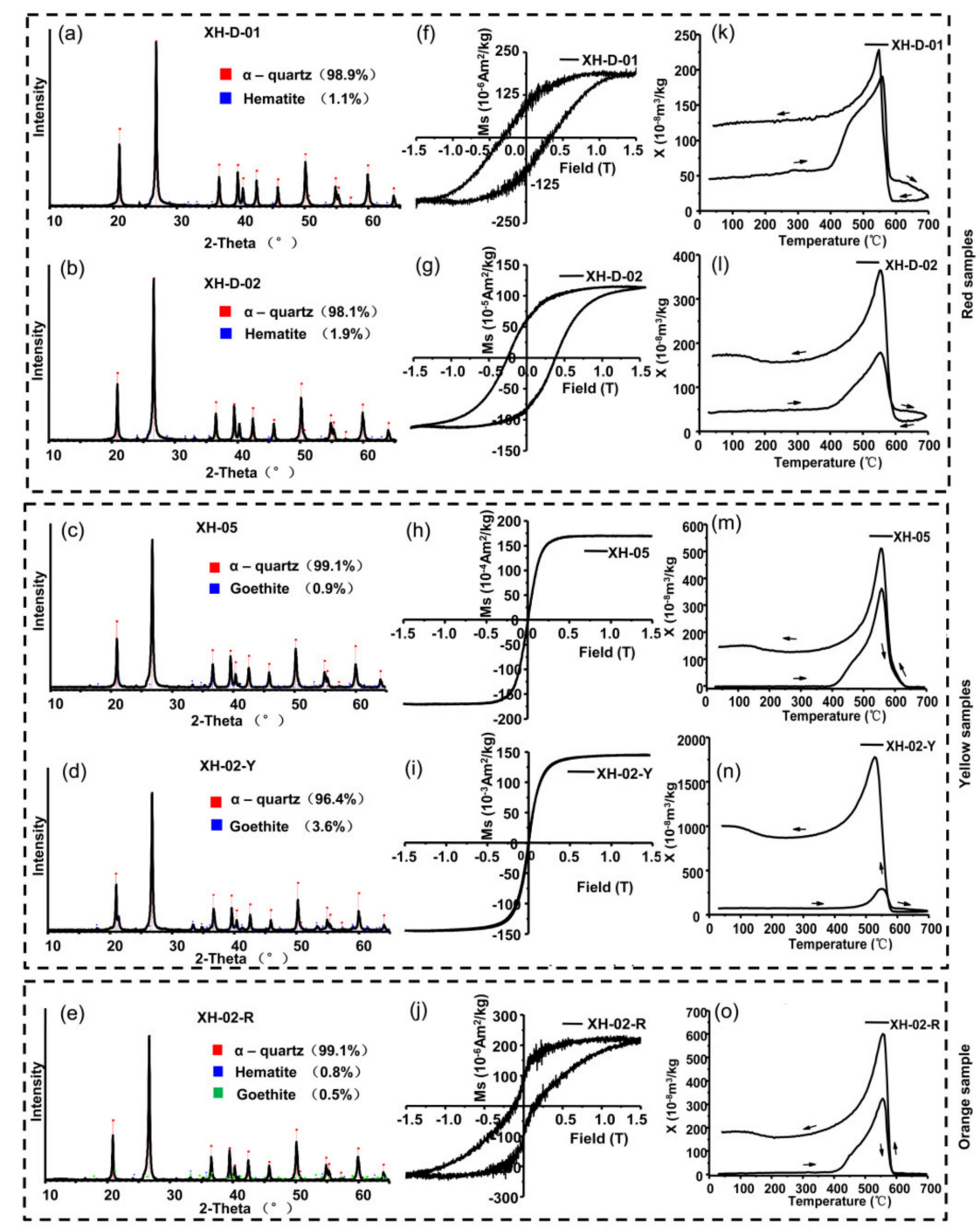

Figure 4. XRD patterns (a-e), hysteresis loops $(\mathbf{f}-\mathbf{j})$ and temperature-dependent susceptibility curves $(\chi-T$ curves, $\mathbf{k}-\mathbf{o})$ of investigated samples.

\subsection{Hysteresis Loop}

Red samples XH-D-01 and XH-D-02 (Figure 4f,g) which contain hematite, do not achieve the saturation in the field up to $1.5 \mathrm{~T}$ and show the coercivity values of $324 \mathrm{mT}$ and $437.8 \mathrm{mT}$, respectively. The coercivity values and the shape of the hysteresis loop are similar to those of natural hematite in soil and sediments [14].

In contrast, yellow samples XH-05 and XH-02-Y (Figure 4h,i) which contain goethite, reach the saturation before $300 \mathrm{mT}$ and have the coercivity values of $3.017 \mathrm{mT}$ and $3.281 \mathrm{mT}$, respectively. The coercivity values and the shape of the hysteresis loop are different from the high coercivity of goethite but similar to those of superparamagnetic magnetite [22].

However, the orange sample XH-02-R (Figure 4j) has the wasp-waisted hysteresis loop with the coercivity of $148.9 \mathrm{mT}$, which results from the mixture of high and low coercivity components [23].

The coercivities of magnetic minerals were found to be linked with the grain size of magnetic particles [14,24]. In this study, the coercivity values of two red samples are $324 \mathrm{mT}$ (sample XH-D-01) and $437.8 \mathrm{mT}$ (sample XH-D-02) measured at room temperature, indicating their average grain size of hematite is likely to be in the range of $0.3 \sim 3 \mu \mathrm{m}$ [14], which is consistent with the grain size from microscopic observation (Figure 3a-c). 


\subsection{Temperature Dependence of Magnetic Susceptibility ( $\chi$-T Curves)}

For red samples XH-D-01 and XH-D-02 (Figure 4k,l), their heating curves between $580{ }^{\circ} \mathrm{C}$ and $700{ }^{\circ} \mathrm{C}$ show obvious decreasing trends, indicating there is magnetism transformation when it is approximately $700{ }^{\circ} \mathrm{C}$. The Néel temperature of hematite is around $685^{\circ} \mathrm{C}[25,26]$ so it can be inferred that there exists some hematite after $580^{\circ} \mathrm{C}$, and this hematite reaches its Néel point when the temperature is approximately $700{ }^{\circ} \mathrm{C}$. However, the cooling curves remain nearly unchanged with lower susceptibility at this range but show the Hopkinson effect and the Curie point of magnetite. These changes suggest that hematite exists before the heating process and its transformation into magnetite during the heating process results in the increase in magnetic susceptibility after experiment at room temperature.

Compared with hematite, the magnetism of goethite is much weaker and the Néel temperature of goethite is usually between $60{ }^{\circ} \mathrm{C}$ and $130{ }^{\circ} \mathrm{C}[27,28]$. Due to the low content, it is difficult to find the sign of the Néel point of goethite in both yellow samples $\mathrm{XH}-05 / \mathrm{XH}-02-\mathrm{Y}$ and the orange sample $\mathrm{XH}-02-\mathrm{R}$ from their $\mathrm{X}-\mathrm{T}$ curves (Figure $4 \mathrm{~m}-\mathrm{O}$ ). However, the different values of susceptibility before and after heat treatment are much higher in yellow samples than those in red samples. The Hopkinson effect is also obvious in yellow and orange samples.

Goethite dehydrates to hematite at $200{ }^{\circ} \mathrm{C} 400{ }^{\circ} \mathrm{C}$ [3] and it was verified that hematite can be transformed into magnetite when heated in an environment with an oxygen fugacity under $10^{-18}[29,30]$. This experiment is performed in an argon atmosphere with low oxygen fugacity which can be regarded as a reducing atmosphere [31], making it possible that hematite and goethite in agate can be converted into magnetite. The color change in investigated samples from yellow/red (common color of goethite and hematite, respectively) to black (common color of magnetite) also verifies this process.

In addition, there is a relationship between the variation degree of susceptibility (the difference value of susceptibility of unit mass samples before and after the $\chi$-T experiment) and the content of hematite and/or goethite (obtained by XRD analysis). Due to the transformation of goethite during the heating process, the variation degree of susceptibility before and after the $\chi$-T experiment among unit mass agate samples with different colors has the following feature (Figure 5): yellow agate (goethite) $>$ orange agate (hematite + goethite) $>$ red agate (hematite). For samples with the same color, the variation degree shows positive correlation with the detected content of hematite and goethite.

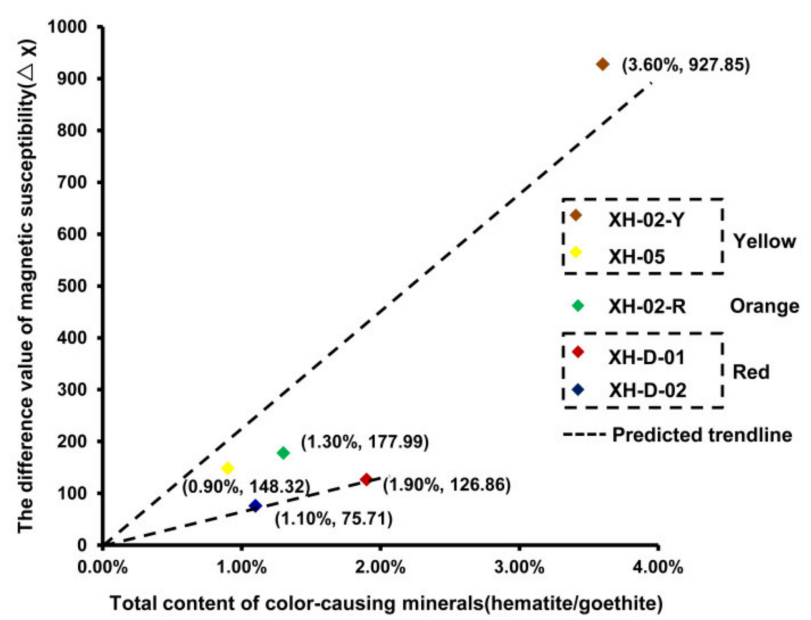

Figure 5. The relationship between total content of hematite and/or goethite and the different values of susceptibility of unit mass samples before and after the $x$-T experiment.

\subsection{Isothermal Remnant Magnetization and Remnant Coercivity Components}

For the red samples (Figure 6a,b), the acquisition curves of isothermal remnant magnetization (IRM) increase continuously and does not saturate before $1.5 \mathrm{~T}$, indicative of the 
contribution of high-coercivity magnetic minerals. However, the IRM acquisition curves of two yellow samples (Figure 6c,d) increase rapidly in the low field and almost saturates before $100 \mathrm{mT}$, which suggests the existence of low-coercivity magnetic minerals. As for the orange sample (Figure 6e), the curve can be divided into two stages due to the contribution of low- and high-coercivity magnetic minerals: (1) the rapid increase before $100 \mathrm{mT}$ reflects the contribution of low-coercivity magnetic minerals; (2) increase in IRM after $100 \mathrm{mT}$ without saturation at $1.5 \mathrm{~T}$ indicates the presence of high-coercivity magnetic minerals.

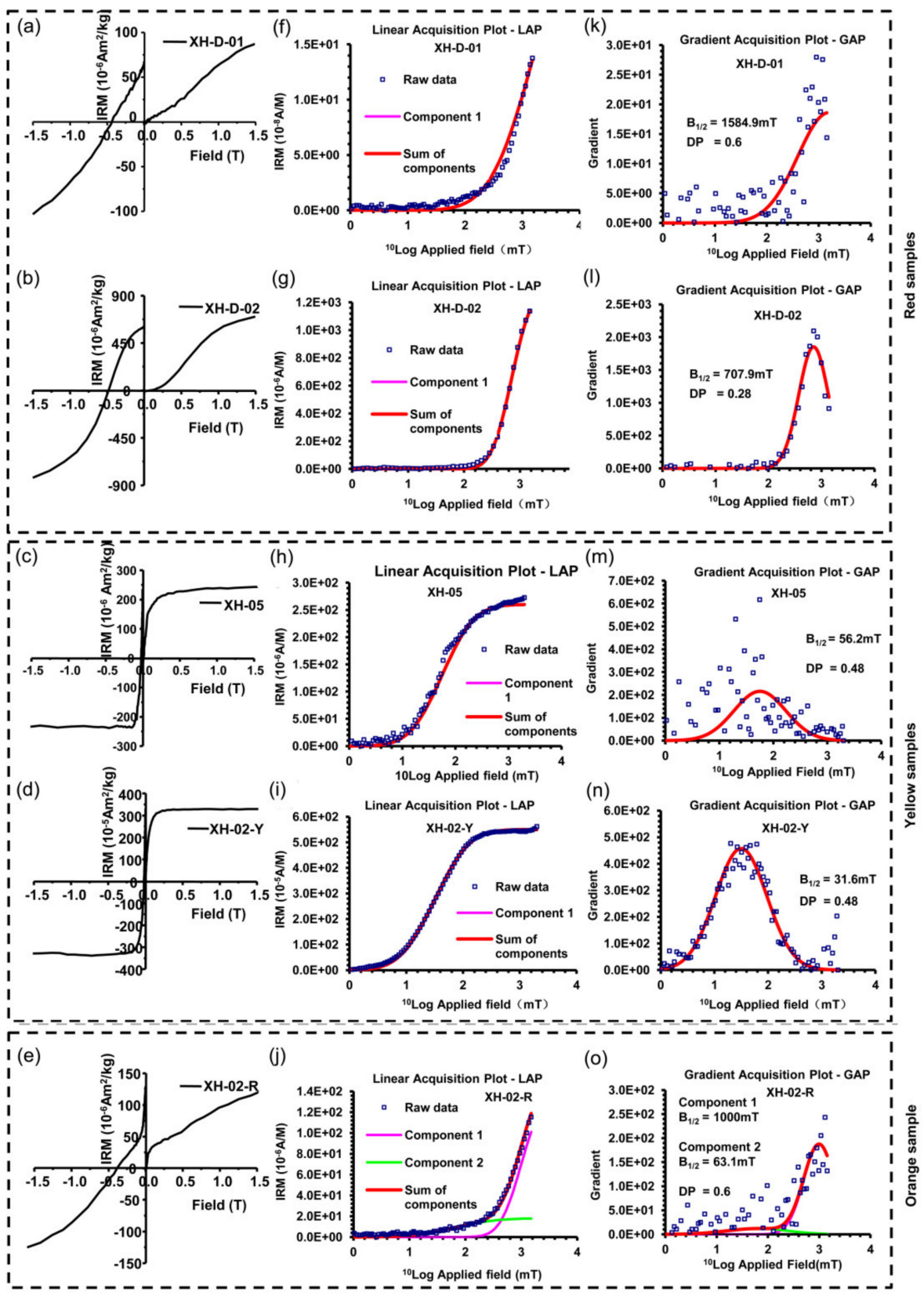

Figure 6. The acquisition curves of isothermal remnant magnetization (IRM) and their back-field demagnetization (a-e), linear acquisition plot (LAP) (f-je and gradient acquisition plot (GAP) (k-o) of investigated samples.

The IRM acquisition curves can be unmixed into magnetic components using the package developed by Kruiver et al. [32]. Figure 6 shows the linear acquisition plot (LAP) (Figure 6f-j) transformed from IRM acquisition curves and the gradient acquisition plot (GAP) (Figure 6k-o) which is the first-order derivation of LAP. The unmixing results clearly 
suggest that the red samples contain only one magnetic component with high remnant coercivity over $700 \mathrm{mT}$ (Figure $6 \mathrm{k}, 1$ ), while the yellow samples contain one magnetic component with low remnant coercivity below $100 \mathrm{mT}$ (Figure $6 \mathrm{~m}, \mathrm{n}$ ). However, the orange sample shows the mixture of a high remnant coercivity component and a low one (Figure 4o), which can confirm the analysis result of its hysteresis loop.

\subsection{Formation Temperature of Xuanhua-Type Agate}

Fluid inclusions in minerals can provide information of its forming condition. It is hard to find fluid inclusions in quartz fibers of agate. However, the quartz druse in the core of agate forms during the last stage, and its fluid inclusions can offer information about the lower limit of agate formation temperature. Based on observation, inclusions in the quartz druse of Xuanhua agate are generally small and the gas-liquid inclusions are relatively rare compared with pure liquid inclusions. In this study, gas-liquid inclusions easy to observe were selected for homogenization temperature measurement (Figure 7). As is shown in Table 1 , the homogenization temperature falls in between $168.8^{\circ} \mathrm{C}$ and $264.0^{\circ} \mathrm{C}$, relatively higher than that of most agate [33-35].
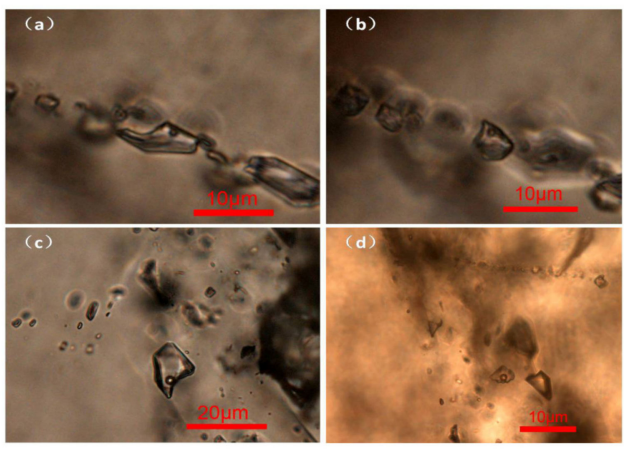

Figure 7. Micrographs of different forms of gas-fluid inclusions (a-d) in the quartz druse of Xuanhuatype agate measured for homogenization temperature.

Table 1. Characteristics of gas-fluid inclusions in quartz druse of yellow to red Xuanhua-type agate.

\begin{tabular}{ccccc}
\hline Picture Number & Inclusion Type & Size $(\boldsymbol{\mu m})$ & $\begin{array}{c}\text { Phase Ratio of } \\
\text { Gas/Fluid (\%) }\end{array}$ & $\begin{array}{c}\text { Homogenization } \\
\text { Temperature }\left({ }^{\circ} \mathbf{C}\right)\end{array}$ \\
\hline Figure 7a & gas-liquid & $5 \times 10$ & 5 & 168.8 \\
Figure 7b & gas-liquid & $6 \times 7$ & 10 & 178.8 \\
Figure 7c & gas-liquid & $12 \times 17$ & 10 & 216.3 \\
Figure 7d & gas-liquid & $3 \times 4$ & 20 & 264.0 \\
\hline
\end{tabular}

\section{Discussion}

For red Xuanhua agate samples whose color are caused by the presence of hematite, the Néel point of $\chi$-T curve near $700^{\circ} \mathrm{C}$ and the characteristics of the hysteresis loop are similar to natural hematite. Their IRM curves and gradient acquisition plots also show the presence of only one magnetic mineral component with high remanent coercivity. Hematite can directly form in the aqueous solution containing iron ions at room temperature or be produced by the transformation of other iron oxides/hydroxides as temperature increases [3]. However, the homogenization temperature measurement of gas-fluid inclusions in this study indicates the formation temperature of these red Xuanhua agate samples is likely to be higher than the temperature range of $168.8^{\circ} \mathrm{C} \sim 264.0^{\circ} \mathrm{C}$.

The remanence coercivity has been reported to be usually under $1000 \mathrm{mT}$ for natural hematite (with the size of $<0.25 \sim 10 \mu \mathrm{m}$ ) formed in soil and sediments [36]. In this study, for the red and orange agate samples, the remnant coercivity values obtained from the hysteresis loops indicates the grain size of their hematite is likely to be in the range of $0.3 \sim 3 \mu \mathrm{m}$. Besides, the remanence coercivity of such agate is approximate to $(\mathrm{B} 1 / 2=707.9 \mathrm{mT}$ for 
XH-D-02) or much higher (B1/2 = $1584.9 \mathrm{mT}$ for XH-D-01; B1/2 = $1000 \mathrm{mT}$ for XH-02-R) than that of natural hematite with a similar grain size (usually under $1000 \mathrm{mT}$ ). It was confirmed that the remanence coercivity of fine-grained hematite derived from goethite (dehydration of goethite between $200{ }^{\circ} \mathrm{C} \sim 400{ }^{\circ} \mathrm{C}$ ) often has very high remnant coercivity which is usually above $1 \mathrm{~T}[3,13,14,24]$. Therefore, it can be inferred that the hematite with a high remanence coercivity (above $1000 \mathrm{mT}$ ) in red agate XH-D-01 and orange agate XH-02$\mathrm{R}$ is likely to be mainly formed by dehydration from goethite, indicating the temperature of the fluid forming such agate probably once reached above $200{ }^{\circ} \mathrm{C}$ which can be verified by the relatively higher homogenization temperature of fluid inclusions in Xuanhua agate.

Yellow and orange agates show no obvious magnetic characteristics of goethite, due to its low content and the weak magnetism. However, from the behavior of hysteresis loop, IRM acquisition curves and the analysis of coercivity components, there is a magnetic mineral with low coercivity (e.g., magnetite or maghemite) $[37,38]$ and extremely low content (under the detection limit of XRD) in such agate. In view of the formation of agate which usually occurs in the closed cavity or pores of surrounding rocks filled by hydrothermal fluid, iron oxides/hydroxides are regarded to be formed during the formation of quartz fibers of agate [2]. For maghemite, it is usually formed by the transformation of other iron oxides / hydroxides above $200{ }^{\circ} \mathrm{C}$ but the phase transformation of goethite also occurs above $200{ }^{\circ} \mathrm{C}$. However, magnetite can be formed with goethite simultaneously at an ambient temperature $[39,40]$. Besides, magnetite was found in the host rocks of such agate samples (Figure 8). Therefore, it can be inferred that the magnetic mineral with low coercivity is magnetite, and its existence confirms the transformation of $\mathrm{Fe}^{2+}$ to $\mathrm{Fe}^{3+}$ during the formation of agate. This transformation indicates the redox property of the forming environment changed during agate formation, which produces various magnetic minerals [3,40]. Based on the unique characteristics, the yellow to red agate from the Xuanhua District can be categorized as the Xuanhua-type agate.
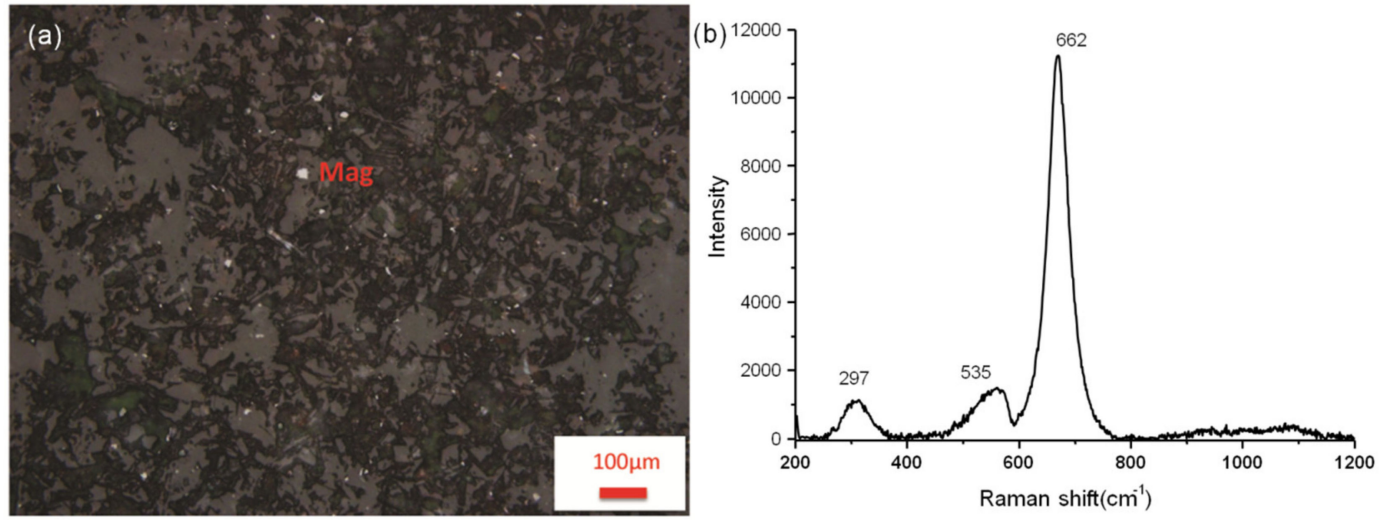

Figure 8. Magnetite in the host rock of yellow agate under reflected light (a) and its Raman spectrum (b).

It is noted that the Xuanhua-type agate is a very popular gem-material. It may have a very bright color in red and yellow, and the two colors are various, occasionally occupying the entire view. Most cut pieces have a certain texture formed by varied components of red hematite and/or yellow goethite, such as dendritic goethite, banded hematite and goethite, displaying a contrasting, changeable and charming landscape, with animal-like and other patterns (Figure 9). The conditions for the formation of iron oxides and hydroxides are determined mainly by variations in the redox potential and $\mathrm{pH}$ of the medium [3]. These patterns within the host agates were likely formed by different temperature, pressure, $\mathrm{fO}_{2}$ and $\mathrm{pH}$ values, and compositions of the parent fluids for formation of each certain individual agate, making the Xuanhua-type agate high in research value in gemology. 

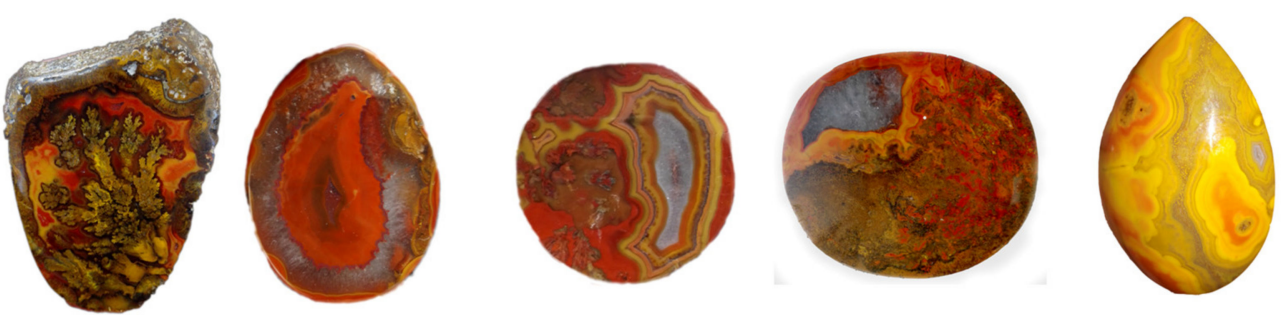

Figure 9. Changeable and charming patterns of the Xuanhua-type agate.

\section{Conclusions}

The magnetic behavior of iron oxides/hydroxides with a relatively higher content in yellow to red Xuanhua-type agate can provide some information about the formation condition, which along with the simple mineral composition makes such agate an excellent material for the study of a hydrothermal environment. The hysteresis loop, isothermal remnant magnetization and analysis of remanent coercivity components offer more nondestructive methods to discuss the genesis of agate and hydrothermal environments rich in iron oxides. All results suggested that the dehydration of goethite to form hematite was the main reason for the high remnant coercivity (above $1000 \mathrm{mT}$ ) of hematite in the red agate. The co-existence of magnetite and goethite in the yellow and orange agate reflects the transformation from $\mathrm{Fe}^{2+}$ to $\mathrm{Fe}^{3+}$, indicating the change in the redox property of the environment. The indication of the magnetic characteristics of iron oxides in agate to the formation condition not only develops the application of rock magnetism to gemology, but also provides more methods to probe into the genesis of different hydrothermal environments. The relationship between the formation environment and the content and magnetic characteristics of iron oxides/hydroxides was preliminarily discussed in this study. However, more samples with similar features from different deposits are required to enrich the conclusion. Changing the forming condition influenced by the external environment produces various and charming patterns mainly displayed by red hematite and yellow goethite aggregates. These patterns make the Xuanhua-type agate a very popular gem-material with high research value.

Author Contributions: Investigation, D.Z., G.S.; writing—original draft preparation, D.Z., G.S.; writing—review and editing, D.Z., G.S., S.L., B.W.; supervision, G.S.; project administration, G.S. All authors have read and agreed to the published version of the manuscript.

Funding: This research was funded by the National Science Foundation of China (41688103), the Second Tibetan Plateau Scientific Expedition and Research Program (2019QZKK0802), and partially funded by NGTC Scientific Research Fund (NGTC2019028).

Institutional Review Board Statement: Not applicable.

Informed Consent Statement: Not applicable.

Data Availability Statement: Data available on request due to restrictions privacy. The data provided in this study can be obtained at the request of the corresponding author. As the data needs further research, the data is currently not publicly available.

Acknowledgments: We thank Juan Liu (Peking University), Taijin Lu and Hua Chen (National Gemstone Testing Center) for their helpful suggestions. Thanks are also given to Shuang Li of Beijing Center for Physical and Chemical Analysis for their assistance in XRD experiments. We are grateful to all reviewers and editors for their constructive and helpful comments, which significantly improved the manuscript.

Conflicts of Interest: The authors declare no conflict of interest. 


\section{References}

1. Götze, J.; Möckel, J.; Kempe, U.; Kapitonov, I. Characteristics and origin of agates in sedimentary rocks from the Dryhead area, Montana, USA. Mineral. Mag. 2009, 73, 673-690. [CrossRef]

2. Meng, G.Q.; Chen, M.H.; Jiang, J.L.; Chen, S. Structural characteristic and cause of colour of "Zhanguohong" agate from Xuanhua, Hebei province. J. Gems Gemol. 2016, 18, 28-34. (In Chinese)

3. Cornell, R.M.; Schwertmann, U. The Iron Oxides: Structure, Properties, Reactions, Occurences and Uses; Wiley: Weinheim, Germany, $2003 ;$ p. 664.

4. Ao, H.; Deng, C.L. Review in the identification of magnetic minerals. Prog. Geophys. 2007, 22, $432-442$.

5. Dekkers, M.J. Environmental magnetism: An introduction. Geol. Mijnb. 1997, 76, 163-182. [CrossRef]

6. Jiang, Z.X.; Liu, Q.S. Quantification of hematite and its climatic significances. Quat. Sci. 2016, 36, 674-689. (In Chinses)

7. King, J.W.; Channell, J.E.T. Sedimentary magnetism, environmental magnetism, and magnetostratigraphy. Rev. Geophys. 1991, 29, 358-370. [CrossRef]

8. Liu, S.Z.; Deng, C.L.; Xiao, J.L.; Li, J.H.; Paterson, G.A.; Chang, L.; Yi, L.; Qin, H.F.; Pan, Y.X.; Zhu, R.X. Insolation driven biomagnetic response to the Holocene Warm Period in semi-arid East Asia. Sci. Rep. 2014, 5, 8001. [CrossRef] [PubMed]

9. Liu, S.Z.; Krijgsman, W.; Dekkers, M.J.; Palcu, D.V. Early diagenetic greigite as an indicator of paleosalinity changes in the middle Miocene Paratethys Sea of central Europe. Geochem. Geophys. Geosyst. 2017, 18, 2634-2645. [CrossRef]

10. Liu, Q.S.; Deng, C.L. Magnetic susceptibility and its environmental significances. Chin. J. Geophys. 2009, 52, 1041-1048. (In Chinese)

11. Zhu, R.X.; Hoffman, K.A.; Nomade, S.; Renne, P.R.; Shi, R.; Pan, Y. Geomagnetic paleointensity and direct age determination of the ISEA (M0r?) chron. Earth Planet. Sci. Lett. 2004, 217, 285-295. [CrossRef]

12. Zhu, R.X.; Lo, C.H.; Shi, R.P.; Shi, G.H.; Pan, Y.X.; Shao, J. Palaeointensities determined from the middle Cretaceous basalt in Liaoning Province, northeastern China. Phys. Earth Planet. Inter. 2004, 142, 49-59. [CrossRef]

13. Dekkers, M.J. Magnetic behaviour of natural goethite during thermal demagnetization. Geophys. Res. Lett. 1988, 15, 538-541. [CrossRef]

14. Özdemir, Ö.; Dunlop, D.J. Hysteresis and coercivity of hematite. J. Geophys. Res. Solid Earth 2014, 119, 2582-2594. [CrossRef]

15. Hu, J.M. Gemological Characteristic of Zhanguo Red Agate from Xuanhua District, Hebei Province. Master's Thesis, China University of Geosciences Beijing, Beijing, China, 2015.

16. Gou, Z.N.; He, X.M. Study on the Coloration of Red-Yellow Zhanguohong Agate from Xuanhua, Hebei Province, China. In Proceedings of the China Gems \& Jewelry Academic Conference, Beijing, China, 30 November 2015.

17. Xu, W.H.; Xu, X.C.; Yang, L.L.; Wu, H.Y. Ore-geology and metallogenesis of 'Zhanguohong' agate from Xuanhua, Hebei Province. J. Gems Gemol. 2017, 19,1-11.

18. Xu, C.; Liang, R.; Yang, X.H.; Zhao, J. Prospecting of agate deposit in Zhangjiakou, Hebei province. J. Gems Gemol. 2017, 19, 17-24.

19. Zhu, R.X.; Xu, Y.G.; Zhu, G.; Zhang, H.F.; Xia, Q.K.; Zheng, T.Y. Destruction of the North China Craton. Sci. China Earth Sci. 2012, 42, 1135-1159. [CrossRef]

20. Zhao, Y.; Xu, G.; Zhang, S.H.; Liu, J.M.; Hu, J.M.; Liu, J.; Pei, J.L. Pre-Yanshanian geological events in the northern margin of the North China Craton and its adjacent areas. Geol. China 2010, 37, 900-915.

21. Zhao, Y.; Zhai, M.G.; Chen, H.; Zhang, S.H. Paleozoic-early Jurassic tectonic evolution of North China Craton and its adjacent orogenic belts. Geol. China 2017, 44, 44-60.

22. Tauxe, L.; Bertram, H.N.; Seberino, C. Physical interpretation of hysteresis loops: Micromagnetic modeling of fine particle magnetite. Geochem. Geophys. Geosyst. 2013, 3, 1-22. [CrossRef]

23. Roberts, A.P.; Cui, Y.; Verosub, K.L. Wasp-waisted hysteresis loops: Mineral magnetic characteristics and discrimination of components in mixed magnetic systems. J. Geophys. Res. Solid Earth 1995, 100, 17909-17924. [CrossRef]

24. Dekkers, M.J. Magnetic properties of natural goethite-I. grain-size dependence of some low- and high-field related rockmagnetic parameters measured at room temperature. Geophys. J. Int. 1989, 97, 323-340. [CrossRef]

25. Dekkers, M.J. Magnetic properties of natural goethite-III. Magnetic behaviour and properties of minerals originating from goethite dehydration during thermal demagnetization. Geophys. J. Int. 1990, 103, 233-250. [CrossRef]

26. France, D.E.; Oldfield, F. Identifying goethite and hematite from rock magnetic measurements of soils and sediments. J. Geophys. Res. Solid Earth 2000, 105, 2781-2795. [CrossRef]

27. Dekkers, M.J. Magnetic properties of natural goethite-II. TRM behaviour during thermal and alternating field demagnetization and low-temperature treatment. Geophys. J. R. Astron. Soc. 1989, 97, 341-355. [CrossRef]

28. Özdemir, Ö.; Dunlop, D.J. Thermoremanence and Neel temperature of goethite. Geophys. Res. Lett. 1996, 23, 921-924. [CrossRef]

29. Shive, P.N.; Diehl, J.F. Thermomagnetic analysis of natural and synthetic hematite. Geophys. Res. Lett. 1977, 4, 159-162. [CrossRef]

30. Wang, T.; Liu, M.X.; Lü, B.; Ma, M.M.; Zhao, G.Y.; Chen, J.S. Study of rock magnetic properties and its variation mechanism of loess in Nileke, Xinjiang. Quat. Sci. 2014, 34, 491-503.

31. Pisutha-Arnond, V.; Rochd, C.; Atichat, W.; Wathanakul, P.; Narudeesombat, N. Role of BE in Reduction and Oxidation Heating of Sapphire. In Proceedings of the 34th International Gemmological Conference, Vilnius, Lithuania, 27-30 August 2015.

32. Kruiver, P.P.; Dekkers, M.J.; Heslop, D. Quantification of magnetic coercivity components by the analysis of acquisition curves of isothermal remnant magnetization. Earth Planet. Sci. Lett. 2001, 189, 269-276. [CrossRef] 
33. Fallick, A.E.; Jocelyn, J.; Donnelly, T.; Guy, M.; Behan, C. Origin of agates in volcanic rocks from Scotland. Nature 1985, 313, 672-674. [CrossRef]

34. Harris, C. Oxygen-isotope zonation of agates from Karoo volcanics of the Skeleton Coast, Namibia. Am. Mineral. 1989, 74, 476-481.

35. Moxon, T.J. Agate: A study of ageing. Eur. J. Mineral. 2002, 14, 1109-1118. [CrossRef]

36. Dekkers, M.J. Some Rockmagnetic Parameters for Natural Goethite, Pyrrhotite and Fine-Grained Hematite. Ph.D. Thesis, University of Utrecht, Utrecht, The Netherlands, 1988.

37. Dunlop, D.J. Theory and application of the day plot (Mrs/Ms versus Hcr/Hc) 1 . Theoretical curves and tests using titanomagnetite data. J. Geophys. Res. Solid Earth 2002, 107, 4-22.

38. Dunlop, D.J. Theory and application of the day plot (Mrs/Ms versus Hcr/Hc) 2. Application to data for rocks, sediments, and soils. J. Geophys. Res. Solid Earth 2002, 107, 5-15.

39. Regazzoni, A.E.; Urrutia, G.A.; Blesa, M.A.; Maroto, A.J.G. Some observations on the composition and morphology of synthetic magnetites obtained by different routes. J. Inorg. Nucl. Chem. 1981, 43, 1489-1493. [CrossRef]

40. Tamaura, Y.; Buduan, P.V.; Katsura, T. Studies on the oxidation of iron (II) ions during the formation of $\mathrm{Fe}_{3} \mathrm{O}_{4}$ and $\alpha-\mathrm{FeO}(\mathrm{OH})$ by air oxidation of $\mathrm{Fe}(\mathrm{OH})_{2}$ suspensions. JCS Dalton 1981, 1807-1811. [CrossRef] 